\title{
O PROGRAMA FOME ZERO E A DISPUTA DISCURSIVA ENTRE O PT E O PFL
}

\section{THE “ZERO HUNGER PROGRAM" AND THE DISCURSIVE STRUGGLE BETWEEN THE POLITICAL PARTIES PT AND PFL}

\author{
Felipe Corral de Freitas ${ }^{1}$ \\ Envio: 25 set. 2011. \\ Aceitação: $29 \mathrm{fev} .2012$.
}

\begin{abstract}
RESUMO
O presente artigo é um estudo sobre o Programa Fome Zero (PFZ), buscando comparar os pronunciamentos dos deputados federais do PT com os do PFL, realizados no grande expediente da Câmara Federal, compreendendo o período do primeiro semestre de 2003. Apresenta como objetivo principal demonstrar como tais deputados de ambos os partidos significam essa política social implementada pelo governo Lula.
\end{abstract}

Palavras-chave: Programa Fome Zero. Teoria do discurso. Posição ideológica.

\begin{abstract}
This paper is a study about the Zero Hunger Programme (Programa Fome Zero - PFZ), which attempts to compare the discourses of deputies from the Workers Party (Partido dos Trabalhadores - PT) and from Liberal Party (Partido da Frente Liberal - PFL) in the House of Representatives. The period of this analysis is from January, 2003 to June, 2003. The main goal is to demonstrate how members of both parties have interpreted this social policy implemented by the Lula government.
\end{abstract}

Keywords: Zero Hunger Program. Discourse theory. Ideological position.

O presente artigo tem como tema o Programa Fome Zero (PFZ), uma política social implementada pelo governo do Partido dos Trabalhadores (PT) em 31 de janeiro de 2003, tendo um grande respaldo tanto da sociedade civil quanto da classe política brasileira. Tido como uns dos principais projetos do então presidente Luiz Inácio Lula da Silva, sendo o seu carro-chefe, o PFZ tinha como principal objetivo dar condições para que todas as pessoas pudessem fazer três refeições diárias, relatado pelo próprio presidente Lula como sendo um sonho seu atingir essa meta como presidente.
Além desse objetivo, o PFZ ainda busca garantir o direito humano à alimentação adequada, promovendo a segurança alimentar e nutricional (SAN), a inclusão social e a conquista de cidadania de todos os brasileiros em situação de vulnerabilidade social. ${ }^{2}$ O programa procura articular ações emergenciais e ações estruturais, indo desde a distribuição de alimentos até mesmo ao incentivo e o barateamento da produção de alimentos no país, um incentivo direto à agricultura familiar, representada pelas famílias inscritas no Programa Nacional de Agricultura Familiar (Pronaf). Ainda estariam envolvidos nessa cadeia os

\footnotetext{
1 Graduado em ciências sociais (Universidade Federal de Pelotas - UFPel), mestrando em ciência política (UFPel)

2 Mais informações sobre o Programa Fome Zero (PFZ) estão no seu site oficial: <http://www.fomezero.gov.br>.
} 
assentados pelo Instituto Nacional de Colonização e Reforma Agrária (Incra).

Primeiramente, o PFZ foi implementado em dois municípios do Piauí, Guaribas e Acauã (semiárido nordestino), considerados entre os municípios mais pobres do Brasil e que apresentavam altos índices de fome por parte da população. Nesses municípios, o PFZ teve um caráter de teste, sendo caracterizado por sua organização como um projeto-piloto. ${ }^{3}$

Quando se fala em PFZ, não se tem como não abordar o conceito de fome. Contudo, neste trabalho o conceito de fome não é o foco central e não será realizada nenhuma construção histórica sobre tal conceito. Segundo o PFZ, a fome ${ }^{4}$ é entendida como um problema social, pois o reflexo da fome no indivíduo não é causado pela falta de produção de alimento, mas sim por um desequilíbrio na distribuição desses produtos, e ainda pela falta de recursos econômicos assim sendo assim, o problema seria social.

Com a ascensão de um partido de esquerda ao comando do Executivo federal, o PT com o governo de Luis Inácio Lula da Silva, logo o Partido da Frente Liberal (PFL) se mostrou um partido oposicionista ao governo Lula. Apesar da base de sustentação do governo ser bastante ampla, a oposição feita pelo PFL é consideravelmente forte, elegendo 84 deputados federais, destacando-se como um partido que sempre elege uma expressiva bancada de deputados.

Por mais que a aliança entre PT e PL (Partido Liberal) descaracterize a tradicional "frente popular", formada somente por partidos de esquerda, já no segundo turno das eleições de 2002 o Partido Trabalhista Brasileiro (PTB) declarou apoio à candidatura do então futuro presidente Lula. Isso não faz com que o governo Lula não represente a esquerda nacional, pois o PT ainda mantém sua posição esquerdista, apesar de não tão radical quanto antes. ${ }^{5}$

\footnotetext{
3 Segundo o site oficial do programa, essa experiência teve uma grande contribuição para formulação do PFZ em nível nacional, pois ali foram identificados alguns problemas que puderam ser corrigidos. Ainda segundo o site, essa experiência tinha como grande objetivo a distribuição de alimentos, compondo a esfera emergencial, mas também procurou incentivar a agricultura local, compondo assim a esfera estrutural do programa.

4 Vários autores trabalham com o conceito de fome. Em torno dessa perspectiva adotada pelo PFZ, destacam-se George (1978), Melo (1983), Castro e Coimbra (1985), Minayo (1987) e Abramovay (1980).

5 Um trabalho importante para se compreender a posição dos partidos de esquerda no Brasil e sua contribuição para a democracia é o de Soares (2006).
}

A esquerda tem muitas características próprias, defendendo políticas como a redução da desigualdade, a melhoria das condições de vida das classes e grupos sociais oprimidos e explorados (LAHORQUE, 2007). Nesse sentido, o PFZ pode ser entendido como uma política de esquerda, pois existe, mesmo que superficialmente, a diferença entre direita e esquerda, categorias universais da política.

Muitas vezes, essa diferença está relacionada ao plano de governo, porque a principal diferença entre elas está relacionada à sua condução de política: enquanto a direita tem um caráter mais conservador, de tradição, a esquerda é apegada à ideia de libertação, de melhorias sociais (BOBBIO, 1995). Ou seja, um partido só é considerado de esquerda quando outro partido se coloca ou se posiciona mais à direita do que o outro. Com isso, mesmo o PT tendo um apoio amplo, não perderia sua característica de esquerda em relação ao PFL.

Já o PFL sempre foi visto como um partido de direita, pois sempre defendeu uma política voltada para um modelo de economia liberal. Suas bases são oriundas do Partido Democrático Social (PDS), antiga Aliança Renovadora Nacional (Arena), partido que fez parte da ditadura militar. Após 1990, o que mais caracteriza um partido conservador são suas políticas voltadas para o mercado, a abertura ao capital estrangeiro, a redução dos gastos públicos, as privatizações (MAINWARING; MENEGUELLO; POWER, 2000).

Pelo fato de haver esses dois polos bem distintos, o PT como situação e o PFL como oposição, foi feita a escolha de compará-los em torno do Programa Fome Zero, construindo assim um campo discursivo em que se busca, de um lado, a legitimação do programa e, de outro, a sua desqualificação. Além de situação e oposição, há uma separação ideológica entre os partidos, pois um é caracterizado como esquerda enquanto o outro, como direita conservadora.

Assim sendo, analisar o PFZ a partir dessa óptica se mostra como um novo olhar sobre tal temática, uma nova construção de como o programa é significado, trazendo uma contribuição para sua discussão. Com isso, o objetivo principal do artigo é analisar os pronunciamentos dos deputados federais do PT e do PFL nas sessões do grande expediente da Câmara Federal no período que compreende o 
primeiro semestre de 2003, entre os meses de janeiro e junho. Tomou-se como base para tal análise os aspectos teóricos e metodológicos de Ernesto Laclau e Chantal Mouffe (2004) e também os aspectos teóricos da análise do discurso de Michel Foucault (1997).

A escolha do grande expediente da Câmara Federal fundamenta-se no fato de ser o momento em que os deputados apresentam seus posicionamentos sobre os temas que estão em pauta no dia. Também é o momento em que os deputados dispõem de um tempo maior para essas discussões. Já o recorte temporal para a análise justifica-se pelo lançamento deste programa de combate à fome ter encontrado maior repercussão no primeiro semestre de 2003, pois foi um dos principais temas defendidos pelo governo Lula em seu primeiro ano de governo.

Para a realização da análise, foram lidos todos os pronunciamentos dos deputados federais do PFL e do PT realizados durante as seções do grande expediente da Câmara Federal entre $1 .^{\circ}$ de janeiro e 30 de junho de 2003. Todos os 84 deputados eleitos pelo PFL e os 91 deputados eleitos pelo PT se pronunciaram, destacando-se que, na grande maioria das vezes, os deputados chegaram a se pronunciar mais de uma vez por expediente. Dentre esses deputados, foram escolhidos os que se referiam ao PFZ, ressaltando que não basta apenas falar do programa, é preciso significá-lo. Dos 84 deputados do PFL, apenas 10 se referiram de forma a significar o PFZ, enquanto dos 91 do PT 18 se pronunciaram tratando do tema. É importante salientar que os deputados usam o grande expediente, na grande maioria das vezes, para tratar de temas que tenham relação direta com seu estado de origem e portanto muitos pronunciamentos abordam temas voltados para o desenvolvimento regional, na busca de atrair atenção e investimentos para o domicílio eleitoral.

O artigo está organizado da seguinte forma: na primeira parte, será apresentado o estado da arte em torno do tema "fome zero"; na segunda parte, serão apresentados os aspectos teóricos da teoria do discurso; posteriormente, será apresentado o debate entre os deputados do PT e do PFL; e por fim, nas considerações finais, será retomado e apresentado, em uma breve conclusão, o objetivo que o trabalho alcançou.

\section{O Programa Fome Zero}

O corte adotado pelo PFZ para caracterizar a linha da pobreza é de $\mathrm{R} \$ 71,53$, considerando pobres aquelas pessoas com renda inferior a aproximadamente US\$ 1,00 por dia (BELICK; DEL GROSSI, 2003). O valor é próximo ao salário mínimo no mês de setembro de 1999, data adotada pela Pesquisa Nacional por Amostra de Domicílios (Pnad) para caracterizar as famílias que não têm renda suficiente para garantir a sua segurança alimentar.

O PFZ busca dar um tratamento universal à questão da alimentação, trazendo à tona o direito à alimentação, ou seja, fazendo com que o Estado seja o provedor de políticas voltadas a esse problema social, como destaca Yasbek (2004), fazendo uma "refilantropização" da questão social, tendo no Estado a instituição garantidora desse direito.

Ainda segundo Yasbek, o PFZ, que surge em um momento de profundas transformações sociais, tem um grande caráter paliativo, pois até esse momento não rompeu com a óptica emergencial.

Yasbek ressalta que um ponto muito importante por parte do PFZ foi colocar em evidência o lugar da pobreza e da fome na sociedade brasileira.

A autora salienta que o direito à alimentação deve ser garantido pelo Estado, mas que isso não descaracteriza o apelo simbólico e humanitário que o programa faz, colocando-o como um programa meramente assistencialista e conservador. Para Yasbek, o programa não traz nenhuma grande inovação em relação aos outros programas sociais já existentes no país, ou seja, ele seria uma continuidade da política social do governo anterior.

Em outro artigo, Yasbek (2003) ressalta ainda mais que a pobreza e o desemprego são as causas principais da fome no Brasil e que, para isso, o PFZ deveria, além de articular outras políticas sociais e estruturais, alterar, até certo ponto, o modelo econômico, fazendo uma relação entre crescimento e distribuição de renda, pois essas seriam duas formas reais de combater esse flagelo ligado diretamente ao poder aquisitivo das pessoas que estão nessa condição. Nota-se, aqui, que o problema da fome não está vinculado à falta de produção de alimentos, mas sim à falta de condições para adquiri-los.

Essa "cruzada solidária" contra a fome, além de ter grande apelo, obteve um consenso social que 
deu grande respaldo ao governo Lula. E, a partir daí, graças a essa força social e ao apelo humanitário do programa, enfrentar-se-ia a pobreza e a fome de forma a erradicá-las - e não apenas abordá-las emergencialmente -, pois, se o problema da fome for tratado como sendo apenas emergencial, corre-se o risco de não se realizar como um "direito social". É preciso, portanto, que esse problema seja politizado para que alcance um status social que justifique a sua apreciação política. A abordagem emergencial é importante, mas é preciso atacar as bases, as estruturas do problema.

Apesar de, em seu lançamento, o programa sofrer críticas acerca de sua estruturação, ele foi apresentado como um programa que envolve todo o governo, articulando ações de todos os ministérios, contando com o Ministério Extraordinário de Segurança Alimentar e Combate à Fome, ${ }^{6}$ tendo propostas de combinar todas as políticas que Yasbek destacou como políticas estruturais, políticas específicas e políticas locais.

Entretanto, segundo Yasbek (2003), as polêmicas e as principais críticas sobre o PFZ são referentes ao seu processo inicial de implementação técnica e política. Uma de suas principais críticas é a burocracia que envolve a abertura de contas bancárias para doações, pela resistência por parte de governos estaduais e municipais em assumir a coordenação regional do programa.

Nunca um governo assumiu o papel de luta e combate à fome com tanta determinação e obstinação como o governo Lula (ANANIAS, 2004). Para o autor, governos anteriores e parte da elite nacional ocultaram o problema da fome, e não tomaram medidas concretas para atacar tal flagelo social. Coube ao governo Lula levantar essa bandeira contra a fome e a exclusão social, tentando eliminar a fome e resgatar a cidadania do povo de baixa renda no Brasil.

Para Ananias, o programa não se restringe à esfera emergencial. Para ele, o PFZ não é meramente assistencialista, pois o que os críticos chamam de assistencialismo nada mais é do que uma política

\footnotetext{
6 Seu ministro e o principal idealizador do Programa Fome Zero foi José Graziano, que elaborou um texto de 132 páginas, contando com a participação de representantes de ONGs, instituto de pesquisa, sindicatos, organizações populares, movimentos sociais e especialistas vinculados à questão da segurança alimentar do país.
}

emergencial, um primeiro momento do programa, pois, como o próprio presidente Lula destacou várias vezes em seus discursos, "quem tem fome tem pressa", ou seja, esse primeiro momento do programa tem uma função muito importante para os assistidos, mas não fica restrito a isso. O PFZ visa à universalização dos direitos da cidadania, tendo como ponto principal o direito à alimentação, mas também outros, tais como os direitos à saúde e à educação, tidos como direitos sociais básicos.

A agricultura familiar assume um papel muito importante no que se refere à produção de alimentos voltada para o programa, pois é por meio dela que será feita a aquisição desses alimentos. Para Ananias, isto ajuda a fixação do homem na terra, garantindo a compra de toda sua produção, fazendo com que o produtor possa ter uma vida digna. Este é um dos tipos de ação previstos no PFZ, articulando não somente o emergencial, mas muito claramente o estrutural do país.

Essas articulações visam a valorizar os cidadãos brasileiros, dando-lhes acesso aos direitos e serviços prestados pelo Estado, colocando os cidadãos no centro do planejamento da ação do Estado (ANANIAS, 2004).

Belick e Del Grossi (2003) destacam que a alimentação é um dos direitos universais do cidadão e o PFZ pretende dar conta disso, sendo equiparado ao direito a educação, saúde e trabalho, e que, na atual Constituição brasileira, o direito à vida deixa implícito o direito à alimentação. Sem dúvida que, para a implementação do programa, ocorreram alguns problemas, pois a abrangência do PFZ é consideravelmente grande. Os autores destacam que um dos maiores problemas foi com relação à seleção do público beneficiário, mas que outros problemas vinculados à sua estruturação, tais como a distribuição de alimentos e a arrecadação de doações, foram sempre corrigidos com muito dinamismo.

Muito próximos do que Yasbek (2004) coloca sobre a posição do Estado com relação ao problema da fome, Belick e Del Grossi (2003) destacam que o Estado, criando um programa que busca erradicar a fome, não está fazendo nada mais que sua função. Com isso, o Estado brasileiro estaria cumprindo uma função constitucional a ele atribuída, pois políticas 
sociais, em muitos casos, são compensatórias em relação ao funcionamento da sociedade, surgindo para compensar as distorções decorrentes do processo de desenvolvimento. Tanto Yasbek (2004) como Belick e Del Grossi (2003) e Ananias (2004) destacam as ações estruturais do programa vinculadas a saúde, educação e infraestrutura, em que a educação tem como alicerce básico o Programa de Alfabetização de Adultos, Requalificação Profissional e Inclusão Digital; já a saúde está alicerçada na área de saneamento básico; na infraestrutura, as principais ações estão voltadas para a agricultura familiar e para a construção de cisternas, um dos problemas enfrentados no programa-piloto realizado em Guaribas e Acauã.

Conforme Graziano da Silva, Belik e Takagi (2003), não é a falta de produção de alimentos o problema da fome no Brasil, mas sim a falta de renda para adquiri-los em quantidade suficiente e permanente. Isso ocorre por haver má distribuição de renda e, com isso, uma grande parte da população brasileira não tem acesso nem mesmo à quantidade mínima de alimentos para sua sobrevivência. A alteração desse quadro passa por uma superação de um ciclo vicioso da fome, em que, desde os anos 1990, vêm ocorrendo políticas que os autores colocam como "bolsa-esmola", havendo apenas uma doação de alimentos e uma pequena quantia monetária. Nesse contexto, o Programa Fome Zero vem para superar essas dificuldades, agindo em três eixos simultâneos: ampliação da demanda efetiva de alimentos, barateamento do seu preço e programas emergenciais para atender a parcela da população excluída do mercado. Com relação às críticas sofridas por parte do PFZ, os autores caracterizam que essas críticas são feitas por haver um desconhecimento dos reais objetivos do programa, ou visando a atingir seu principal inspirador, que é Lula.

A partir dessa construção sobre o que tem se falado sobre o Programa Fome Zero, busca-se relacionar o posicionamento do PFL e do PT, com base nos pronunciamentos dos seus deputados federais realizados no grande expediente da Câmara Federal no primeiro semestre de 2003 . Na próxima seção do artigo, serão apresentados, brevemente, os aspectos teóricos e metodológicos da teoria do discurso, destacando as contribuições feitas por Michel Foucault, Ernesto Laclau e Chantal Mouffe.

\section{A teoria do discurso}

Após fazer uma apresentação sobre o estado da arte em torno do PFZ, agora será apresentada a base teórica utilizada para realizar as análises dos discursos selecionados. Trata-se da teoria do discurso, inspirada na obra do filósofo argentino Ernesto Laclau e da filósofa belga Chantal Mouffe, Hegemonia e estratégia socialista (2004).

Laclau tem algumas obras publicadas com Chantal Mouffe, sendo Hegemony \& socialist strategy: Towards a radical democratic politics, publicada em 1985 pela editora inglesa Verso e em 2004 editada em espanhol pela Editora Fondo de Cultura Econômica da Argentina com o nome de Hegemonia y estrategia socialista: Hacia una nova radicalización de la democracia, a obra que marcou o ponto de partida da teoria do discurso.

Vindos da tradição marxista, sobretudo orientados a partir das obras de Antonio Gramsci e Louis Althusser, Laclau e Mouffe rompem, mas não completamente, com tal tradição, mais precisamente com a sua ideia economicista. O conceito de sobredeterminação de Althusser foi uma peça fundamental para se buscar uma análise dessa teoria sem cair no mero reducionismo econômico. Segundo Althusser (1985), não há nada no social que não esteja sobredeterminado, com o social se constituindo em uma ordem simbólica, e que essa constituição simbólica se dá a partir da ideologia que, segundo Althusser, é “uma 'representação' da relação imaginária dos indivíduos com suas condições reais de existência". (ALTHUSSER, 1985, p. 85).

Mesmo com o conceito de sobredeterminação, Althusser não rompe totalmente com a teoria marxista, pois no fundo ele ainda não rompia com o determinismo econômico que em última instância o seu conceito de sobredeterminação supunha superar. Assim, a partir de Hegemonia y estrategia socialista, Laclau e Mouffe adotam uma linha crítica à teoria marxista, mas não o abandono completo de suas categorias, iniciando-se, dessa forma, uma corrente teórica pós-marxista.

Com a influência do pós-estruturalismo, principalmente de autores como Derrida e Lacan, Laclau e Mouffe dão continuidade à teoria do discurso com outras publicações, destacando as realizadas por Laclau, pois o autor busca ampliar o entendimento 
de sua teoria. Nuevas reflexiones sobre la revolución de nuestro tiempo (2000), Emancipación y diferencia (1996) e La razón populista (2005) foram publicações em que Laclau aprofundou ainda mais a teoria do discurso. E junto com Judith Butler, organizadora do livro, e Slavoj Zizek, Laclau publicou Contingency, hegemony, universality (2000).

Após essa breve apresentação sobre a origem dos principais conceitos trabalhados pela teoria do discurso, os quais vão ser apresentados agora, busca-se com isso apresentar como se dão as formações discursivas, como um discurso se forma a partir do social, pois, segundo Laclau, tudo no social é discursivo.

Para Laclau e Mouffe (2004), um discurso é uma prática articulatória e significativa que constitui e organiza relações sociais. Essas práticas articulatórias buscam construir pontos nodais, os quais fixam parcialmente sentidos, sendo assim que toda produção de sentidos depende de uma estrutura discursiva.

$\mathrm{O}$ discurso busca articular elementos diferentes e dispersos no campo da discursividade. O campo discursivo é o espaço em que diversas formações discursivas entram em concorrência umas com as outras, formado um jogo de equilíbrio instável entre diversas forças (MAINGUENEAU, 2000). Um discurso se forma sempre na tentativa de dominar o campo da discursividade, buscando se constituir como um ponto nodal.

É por meio de práticas articulatórias, dentro desse campo discursivo, que elementos se transformam em momentos, pois antes da prática articulatória eles se encontravam dispersos, não articulados. Portanto, quando um elemento se articula com outro ele passa a ser um momento, modificando a sua identidade inicial, alterando os seus conteúdos particulares anteriores. É a partir dessa articulação de elementos que formam momentos, em que suas identidades acabaram sendo modificadas pela articulação com outro elemento disperso no campo da discursividade, que se origina, que se constitui o discurso, ou seja, o resultado da prática articulatória é o discurso. Ainda vamos ver que todo discurso se constitui a partir de seu antagônico, de outro discurso contrário (LACLAU; MOUFFE, 2004).

Em uma prática articulatória, a transformação de elementos em momentos nunca é completa, ou seja, ela modifica a sua característica anterior quando há a articulação, anulando as suas particularidades de elementos, mas isso não significa que aquilo que ela apresentava de diferente acabou, ou seja, as identidades não deixam de existir como elementos diferentes - muito pelo contrario, pois a prática articulatória se dá pelas diferenças que, em um determinado momento, juntaram-se em um ponto nodal. Em um segundo momento, quando essa articulação em um ponto nodal acaba, ela volta a ter as suas diferenças, por mais que essas diferenças tenham sofrido alguma modificação por causa da articulação (LACLAU; MOUFFE, 2004). Portanto, a articulação fixa apenas sentidos parciais, que são precários e contingentes.

A teoria do discurso de Ernesto Laclau e Chantal Mouffe, uma teoria pós-estruturalista, como afirmado acima, percebe a precariedade e a contingência dos sentidos gerados a partir de um determinado discurso. As verdades são construídas discursivamente e podem mudar com o passar do tempo, ou seja, não é uma verdade para todo o sempre. Portanto, todos os sentidos devem ser entendidos dentro de seu contexto e a partir de suas condições de emergência.

Até este momento, demonstramos como um discurso vai se constituindo com tal, como os elementos dispersos em um campo discursivo se articulam com outros, formando momentos, e como esses momentos formam um discurso por meio dessa prática articulatória.

O ponto nodal de uma formação discursiva assume uma característica importantíssima na construção do discurso. É por meio do ponto nodal que se estabelece a união entre os momentos diferencias, pois é esse ponto nodal, um ponto discursivo privilegiado, o qual vai aglutinar outros discursos em torno de si. Ele também é o determinante dos limites desse discurso, do que está articulado e não está articulado, ou seja, o que ele representa e o que não representa.

É nesse momento que podemos perceber outro importante conceito da teoria do discurso, o conceito de hegemonia, pois todo discurso busca se hegemonizar, ou seja, uma identidade tenta impor sua particularidade sobre a outra, mesmo que seu sentido nunca seja plenamente constituído, e é disso que decorre a impossibilidade de totalização.

Um discurso hegemônico é sempre um discurso sistematizador, pois aglutina outros sentidos, ou seja, hegemonia é quando uma identidade, de maneira precária e contingente, passa a representar 
diversas outras identidades dentro desse discurso. Por isso, essa aglutinação de outras identidades, o discurso original sempre acaba se alterando, já que entra em contato com novas identidades, abarcando novos sentidos, fazendo com que seu conteúdo original se altere, visto que para buscar essa hegemonia ele tem de ampliar seus conteúdos.

Outro conceito fundamental para a teoria do discurso é o de antagonismo. A noção de antagonismo parte da impossibilidade da objetivação de qualquer identidade, não havendo uma relação entre identidades plenas. A existência de um discurso necessita obrigatoriamente de seu antagônico, ou seja, o discurso A só existe porque existe um discurso oposto, antagônico a ele, o discurso B. Assim, o discurso se constitui em oposição ao seu negativo, ao seu concorrente. E é esse concorrente, esse antagonismo discursivo, ou seja, a presença do outro que impede um determinado discurso de ser totalmente ele mesmo (LACLAU; MOUFFE, 2004).

Dentro dessa disputa discursiva, um discurso nega o outro, formando sentidos opostos. Um discurso nunca vai articular características de seu antagônico, pois estaria negando a si mesmo. Portanto, discursos antagônicos não possuem conteúdos comuns; logo, toda formação discursiva tem bloqueada sua expansão de sentidos pela presença de seu corte antagônico.

Toda produção de sentido, como vimos, é precária e contingente. Precária porque os sentidos produzidos por um sistema discursivo sempre sofrem alterações em seus conteúdos quando entram em contato com outros discursos dispostos no campo da discursividade. Já a contingência se dá por não ser possível prever os sentidos gerados no espaço social, ou seja, o que hoje é significação de uma forma, amanhã pode mudar radicalmente. Algo que é visto como positivo nos dias de hoje, amanhã pode se tornar negativo.

Todo discurso busca no final a sua universalização, tentando preencher todos os sentidos que possibilitem sua total universalização, mas, como vimos, essa universalização é uma impossibilidade. Tanto a precariedade e a contingência como o seu corte antagônico impossibilitam um determinado discurso de conseguir a sua universalização.

A noção de lógica da equivalência, dentro da teoria do discurso, demonstra que determinado aspecto fez com que diferentes elementos se articulassem.
No campo discursivo, a lógica da equivalência faz com que elementos se articulem, ou seja, é o mesmo desejo, a mesma finalidade.

Por exemplo, vejamos a disputa dos arrozeiros, aliados com o Movimento dos sem Terra (MST) contra a silvicultura, a partir do trabalho de Roberto Vieira Júnior (2009). Neste casoa articulação era contra a plantação de eucalipto no estado do Rio Grande do Sul, ou seja, a lógica da equivalência articula identidades diferentes, antes regidas pela lógica da diferença, em torno de um ponto nodal. Essa articulação, antes de ter esse elemento comum da ideia contrária à silvicultura, era vista como impossível, pois se tratavam de dois discursos antagônicos, mas que, a partir desse ponto comum, acabaram se unindo contra essa prática de monocultura.

Nesse exemplo, percebe-se claramente que tanto a lógica da equivalência, o que se articula a partir de um determinado assunto ou interesse em comum, como até mesmo o antagonismo são precários e contingentes. Dois discursos historicamente antagônicos (arrozeiros e MST) se aliam em torno de um ponto nodal, demonstrando que não existem conteúdos formados para todo o sempre, mas que, na verdade, para a teoria do discurso, os conteúdos são construções discursivas que devem ser entendidas em contextos históricos específicos.

Já a lógica da diferença é exatamente o momento anterior a essa articulação. Essas duas identidades, os arrozeiros e o MST, que anteriormente operavam pela lógica da diferença, a partir de um determinado momento em que buscaram e defenderam os mesmos interesses, passaram a ser conduzidos pela lógica da equivalência.

Outra noção de grande importância para a teoria do discurso é a de significante vazio. Segundo Laclau, "o significante vazio é um significante sem significado" (LACLAU, 1996).

Um determinado discurso, um ponto nodal, abarca tantos significados de vários momentos que se articularam em torno de si, de várias identidades que articularam em torno de si, que acaba esvaziando as suas particularidades e representando outras particularidades dessas identidades com ele articuladas. Com isso, esse discurso se torna um significante sem significado, pois na verdade representa muitas outras identidades, mas nenhuma única em particular, tornando-se um significante vazio. 
Portanto, é a partir desses conceitos apresentados que a teoria do discurso está plasmada. É a partir desse enfoque teórico que o artigo está fundamentado. Dessa forma, o PFZ será visto como o ponto nodal, ou seja, o ponto discursivo privilegiado no qual os antagonismos produzidos nos pronunciamentos dos deputados do PFL e do PT articularão duas cadeias de equivalências discursivas.

Outro autor utilizado para a análise dos dados foi Michael Focault. A partir de agora, serão apresentados os aspectos da teoria do discurso de Foucault, destacando o conceito de regularidade na dispersão, fundamental para a articulação dos dados e, com isso, a elaboração do artigo.

Para Foucault, o discurso se forma por meio das regularidades na dispersão. As unidades de um discurso estão dispersas, ou seja, essa unidade é uma construção em que as regularidades na dispersão do discurso vão construir as "verdades", pois as regularidades conduzem a uma certa verdade, as suas verdades (FOUCAULT, 1997).

Segundo Foucault, são os enunciados que devem ser buscados em um discurso, pois o enunciado sobre determinado discurso é o que está sendo significado sobre esse discurso.

$\mathrm{O}$ autor destaca ainda que o discurso não tem de ser entendido ao longo da história, mas sim no momento em que é dito. Não existe uma historia linear do objeto, ele está disperso em vários meios. Ainda segundo Foucault, o que se busca em um discurso é o que foi dito, não o que estaria "entre linhas", uma conversa obscura, mas sim o que está claro, o que está manifesto.

Dentro do discurso e seus enunciados, o que se busca é compreender o enunciado, "não se busca, sob o que está manifesto, a conversa semissilenciosa de outro discurso" (FOUCAULT, 1997). A função do arqueólogo é encontrar as verdades cientificas, descrever o discurso e não desvelá-lo, não buscar as entrelinhas.

Os enunciados formam um conjunto quando se referem ao mesmo objeto (ex: loucura), e o que está em jogo não é o objeto em si, mas o significado a ele dado. Uma questão que Foucault coloca é como apareceu um determinado enunciado e não outro em seu lugar?

Isso é o que Foucault chama de condições de emergência, em que essas condições são dadas pela estrutura, pois nem tudo pode ser dito a qualquer momento, e essas condições fazem o discurso ser dito naquele momento (FOUCAULT, 1997).

A partir desses aspectos da teoria do discurso se buscou a seleção dos pronunciamentos, sempre procurando as regularidades e seus enunciados dispersos no campo da discursividade, e, por fim, demonstrando seu corte antagônico, a sua disputa discursiva. Com isso, a análise se concentrou nas regularidades dos argumentos utilizados pelos deputados para significar o PFZ. Logo, com as regularidades já articuladas, formando o discurso, foram separadas em favoráveis e contrárias ao programa, caracterizando o corte antagônico entre os pronunciamentos dos deputados do PFL e do PT. Portanto, os pronunciamentos foram separados dentro de cada sigla e logo separados entre os que apoiavam e os que eram contrários ao PFZ, para, após, realizar uma análise mais profunda na busca de evidenciar quais argumentos eram utilizados para defender e quais eram utilizados para criticar o PFZ, os quais serão apresentados nas seções subsequentes do artigo.

\section{PFL: uma análise crítica do PFZ}

Neste momento, será feita uma análise dos argumentos utilizados pelos deputados federais do PFL para caracterizar o Programa Fome Zero, buscando demonstrar como esses deputados significam o PFZ. Dos dez deputados do PFL que significaram o PFZ, foram utilizados os pronunciamentos de seis, buscando destacar o sentido dado por tais deputados com relação ao programa, construindo a regularidade na dispersão.

A grande maioria dos deputados do PFL utiliza o argumento do assistencialismo para significar e criticar o PFZ, destacando que para eles não basta dar comida, o programa tem de buscar outras articulações, tais como aumento da produção, melhora da educação, entre outras. O retrocesso econômico também é colocado como um dos fatores da fome em nosso país e, para superar esse flagelo, seria necessário combater esse atraso e não apenas distribuir alimento.

Outra crítica recorrente contra o PFZ é com relação aos gastos excessivos, tanto com propagandas na mídia como em implementação do programa. A partir desse argumento, os deputados do PFL 
buscaram fazer uma ligação com o pagamento dos juros da dívida externa, pois, para os críticos do programa, o governo deveria diminuir, ou até mesmo suspender, o pagamento dos juros e investir no PFZ.

A crítica ao assistencialismo sem dúvida é mais recorrente no discurso crítico ao PFZ, sendo que a grande maioria aponta para um programa que visa apenas às necessidades momentâneas do assistidos pelo PFZ, ou seja, o programa acaba sendo caracterizado como meramente assistencialista, como podemos ver pelo pronunciamento de Rogério Nunes (PFL-BA):

É necessário que o governo do presidente Lula, tão empenhado no combate à fome, tome consciência de que dar condições de produzir, de contribuir para a formação da riqueza nacional é tão ou até mais importante e efetivo do que dar alimento para matar a fome de agora, sem previsão para a de amanhã. (DIÁRIO DA CÂMARA DOS DEPUTADOS, 26 fev. 2003, p. 04220).

É melhor ensinar a pescar do que dar o peixe a quem tem fome, diz o velho ditado. Para isso, senhora presidenta, senhoras e senhores deputados, é fundamental ter onde pescar. (DIÁRIO DA CÂMARA DOS DEPUTADOS, 26 fev. 2003, p. 04221).

Nota-se, nesse pronunciamento, que o deputado Rogério Nunes não só caracteriza o programa como assistencialista como também demonstra, em sua opinião, como o governo Lula deveria agir para concretizar uma real luta contra a fome.

Segundo esses argumentos, que colocam o PFZ como meramente assistencialista, não basta prover o alimento, como podemos perceber em mais um pronunciamento, desta vez de Machado (PFL-SE), o qual significa o programa como assistencialista:

Pessoalmente, fico satisfeito quando vejo o grande mutirão do governo federal para distribuição de comida, por meio de ações como Fome Zero. Quero apresentar uma sugestão ao presidente Lula: como nordestino, e muito bem intencionado, empenhe toda a sua força popular e política para promover um mutirão de empreendimentos para o Nordeste. Mande-nos indústrias, estabeleça política diferenciada para o setor agrícola nordestino... - fortaleça o comércio e o setor de serviços. Assim, teremos onde trabalhar, o que comer e onde morar decentemente. (DIÁRIO DA CÂMARA DOS DEPUTADOS, 13 maio 2003, p. 19913).
O deputado Machado demonstra, em seu pronunciamento, a importância de se ter um programa que busque distribuir alimentos para aquelas pessoas que não têm condições financeiras de adquiri-los, e ainda apresenta sugestões para que o programa tenha efeito mais amplo, de um efetivo combate à fome, destacando que o governo realize um "mutirão de empreendimentos".

Outra característica colocada para definir o PFZ como assistencialista é voltada para a área da economia, sendo mais específica ainda, destacando a geração de emprego, como relata o deputado Osório Adriano (PFL-DF):

Onde estão os dez milhões de empregos prometidos? Quando se iniciará a retomada do desenvolvimento? Não é com migalhas de doações para combater a fome que podem ser compensadas socialmente as malévolas consequências do retrocesso econômico. (DIÁRIO DA CÂMARA DOS DEPUTADOS, 21 jun. 2003, p. 28381-82).

O deputado Osório Adriano destaca que o retrocesso econômico em que se encontra o país não vai ser superado com "migalhas de doações para combater a fome", pois, segundo ele, a grande culpa de haver fome em nosso país se deve, de fato, a esse retrocesso, e políticas de doação de alimentos não vão compensar esse problema social.

Outra característica é apontada no pronunciamento do deputado Costa Ferreira (PFL-BA), oportunidade em que ele coloca que "combater a fome sem atacar as causas do atraso é mero paternalismo" (DIÁRIO DA CÂMARA DOS DEPUTADOS, 02 abr. 2003, p. 1499). Com isso, Costa Ferreira destaca que o PFZ busca apenas a distribuição de alimentos, o que não passa de paternalismo por parte do governo Lula.

Umas das críticas mais contundentes ao Programa Fome Zero é com relação aos excessivos gastos referente à sua implementação, como destaca a deputada Nice Lobão (PFL-MA):

Ora, senhor presidente, o Fome Zero está patinando há cinco meses, gastando uma fábula em viagens e diárias com os funcionários responsáveis pela sua implantação, sem resultados concretos até o presente momento. (DIÁRIO DA CÂMARA DOS DEPUTADOS, 05 jun. 2003, p. 25446).

A deputada reclama que o programa tem gasto muito dinheiro sem ter um resultado concreto para 
a sociedade, ficando mais claro seu posicionamento neste trecho de seu pronunciamento: "Basta ao governo, se quiser seriedade com o assunto, reduzir o religioso pagamento de juros da dívida externa e canalizar esses recursos para reduzir o desemprego e a fome no país" (DIÁRIO DA CÂMARA DOS DEPUTADOS, 05 jun. 2003, p. 25446). Nesse sentido, para a deputada Nice Lobão, o PFZ não é um efetivo programa que busca atacar a fome com seriedade.

Portanto, percebemos a partir dos pronunciamentos dos deputados federais do PFL que o PFZ não passa de meramente assistencialista e, ainda, o governo Lula é acusado de paternalismo.

Nota-se também que em nenhum momento os deputados se posicionaram contra o combate à fome, pelo contrário: em certos momentos, destacaram a grande iniciativa do governo Lula em buscar combater este flagelo brasileiro, como podemos perceber no pronunciamento do deputado Milton Barbosa (PFL-BA):

\begin{abstract}
Muito embora também reconheça que o Programa Fome Zero começou marcado por uma série de confusões de concepção, de organização e funcionamento operacional, sou daqueles que se dispõem a se engajar na correção de suas deficiências, buscando retomá-lo para ações que obtenham, de fato, sucesso, trazendo benefícios aos mais de dez milhões de famílias brasileiras carentes de alimentos e equilíbrio nutricional. (DIÁRIO DA CÂMARA DOS DEPUTADOS, 16 abr. 2003, p. 15077).
\end{abstract}

O deputado se posiciona favorável ao PFZ, apesar de haver alguns problemas quanto a sua concepção, organização e operacionalização.

Com isso, mesmo o combate à fome por meio do PFZ sendo uma atitude de grande importância, tendo um caráter elogiável, as críticas à sua implementação e sua estruturação são fortes. Na visão dos deputados citados, o PFZ não passa de uma política pública meramente assistencialista e não busca tratar outros problemas paralelos, como o retrocesso econômico e a falta de emprego e renda.

\section{PT: respondendo as críticas}

O PT, partido do então presidente da república, Luiz Inácio Lula da Silva, por meio de seus deputados federais demonstra um posicionamento sempre em defesa frente aos ataques ao Programa Fome
Zero. Muitas vezes esses ataques acabam, até certo ponto, demonstrando as fragilidades do PFZ. Para os petistas, trata-se de um programa que busca articular muitas ações, como a integração de todos os ministérios do governo para o combate à fome, a geração de emprego e renda, políticas de estruturação em outras áreas como a agricultura familiar, entre outros aspectos já mencionados. Dentre os 18 deputados que significaram o PFZ, foram utilizados os pronunciemos de 6 deles para a elaboração desta seção, buscando destacar a regularidade nesses pronunciamentos.

Segundo os deputados petistas, essas críticas são naturais pela circunstância de o programa ter uma grande dimensão, abrangendo muitas medidas estruturais, que passam não só pelo governo federal mas também pelos governos estaduais e municipais. Outro argumento utilizado para defender o PFZ é com relação ao aumento da produção agrícola no país, sendo ações articuladas ao PFZ. Destaca-se, ainda, a ideia de inclusão do programa, pois, segundo os seus defensores, ele busca incluir a população pobre na sociedade, dando-lhe um direito básico de cidadania.

$\mathrm{O}$ argumento que fecha essa defesa sem dúvida nenhuma é do impacto do PFZ no mundo, fazendo com que representantes políticos internacionais debatessem esse projeto e tivessem uma visão positiva sobre o tema de combate à fome no Brasil.

Isso fica bem claro no pronunciamento da deputada Maria do Carmo Lara (PT-MG):

Em que pesem os problemas e as críticas inicias, naturais na estruturação de um programa dessa dimensão, hoje, o Fome Zero começa a mostrar que tem capacidade de se desenvolver com eficiência e eficácia. E este programa não se restringe à esfera governamental somente; ele faz uma convocação, uma mobilização de toda sociedade para superar a principal vergonha e indignidade de todo o Brasil - a fome. (DIÁRIO DA CÂMARA DOS DEPUTADOS, 03 jun. 2003, p. 24683).

A deputada destaca que as essas críticas ao PFZ são naturais pelo fato de o programa ter uma grande dimensão e, mesmo sofrendo essas críticas, ele já demonstra capacidade de ser bem-sucedido.

O mesmo tipo de argumento pode ser percebido no discurso do deputado Leonardo Monteiro (PT-MG): 
Um verdadeiro caos foi assumido por Lula, que não se intimidou com os problemas e tomou medidas imediatamente, como o lançamento do Programa Fome Zero, que vai muito além do que distribuir cartões e comida; visa à implementação de uma política de aumento da produção agrícola com a geração de emprego e renda, de cidadania e alfabetização. (DIÁRIO DA CÂMARA DOS DEPUTADOS, 28 maio 2003, p. 23411).

Para o deputado Leonardo Monteiro, o presidente Lula, além de ter assumido a presidência da república em um caos, encarou o problema da fome em seu primeiro instante como presidente, destacando ainda que o PFZ vai muito além d a simples distribuição de alimentos. Ele visa, na verdade, a uma gama de ações, como "aumento da produção agrícola com a geração de emprego e renda”, de cidadania e alfabetização. Portanto, o Programa não se restringe à esfera emergencial.

Essas políticas articuladas que compõem o PFZ fazem parte das várias ações que buscam atacar o cerne do problema, demonstradas pelo deputado Josias Gomes (PT-BA):

Felizmente, a sociedade brasileira aderiu e acolheu em boa hora o Fome Zero, composto por dezenas de ações integradas que estão sendo implementadas de forma gradativa. O ministério deu início ao projeto-piloto nas cidades de Guaribas e Acauã e não só com a distribuição de cartão; programas acessórios a ele estão sendo desenvolvidos, para que se possa, a partir dali, desenvolver gradativamente o Fome Zero em todas as suas áreas. (DIÁRIO DA CÂMARA DOS DEPUTADOS, 29 mar. 2003, p. 10895).

Com isso, o deputado destaca que a sociedade aderiu ao PFZ e que, por meio do projeto-piloto nas cidades de Guaribas e Acauã, estão sendo desenvolvidos programas acessórios e que vão ser desenvolvidos gradativamente.

No seu pronunciamento, o deputado Fernando Ferro (PT-PE) demonstra claramente dar um resposta às críticas feitas ao PFZ, pois, para ele, "o Fome Zero não é um programa assistencialista, mas de inclusão, de geração de emprego e renda, que confere a cidadania”. (DIÁRIO DA CÂMARA DOS DEPUTADOS, 05 abr. 2003, p. 12726).

Outro aspecto salientado pelos parlamentares petistas é com relação ao impacto e à repercussão que o PFZ teve em todo o mundo, como coloca o deputado Vignatti (PT-SC):

O Brasil surpreendeu o mundo quando o presidente Luiz Inácio Lula da Silva foi ao Fórum Econômico Mundial, em Davos, e, apresentando o Projeto Fome Zero, conclamou os chefes de Estados dos países mais ricos do mundo a integrarem um programa audacioso de combate à miséria e à fome. Ganhou respeito e admiração dos estadistas como Jacques Chirac e Vladimir Putin e do secretário-geral da ONU, Kofi Annan. (DIÁRIO DA CÂMARA DOS DEPUTADOS, 02 abr. 2003, p. 11506).

Segundo o deputado Vignatti, o projeto, além de ser audacioso, surpreendeu chefes de Estados importantes, como o francês Jacques Chirac e o russo Vladimir Putin, ganhando respeito internacional também de Kofi Annan, secretário-geral da ONU. Em outra passagem de seu pronunciamento, Vignatti ressalta o impacto positivo do PFZ ao ser anunciado no Fórum Econômico Mundial:

O Programa Fome Zero ganha repercussão internacional e agenda organismos como a própria $\mathrm{ONU}$ e a OEA. A proposição de combate à miséria e à fome foi aplaudia e ganhou apoio de chefes de Estado no Fórum Econômico Mundial, realizado no mês de janeiro, em Davos, na Suíça. (DIÁRIO DA CÂMARA DOS DEPUTADOS, 02 abr. 2003, p. 11507).

Com relação a esse impacto internacional do PFZ, o deputado Assis Miguel do Couto (PT-PR) destaca ainda mais essa característica em seu pronunciamento: "Em seu primeiro discurso como presidente, Lula anunciou e está colocando em prática o Programa Fome Zero, que visa [a] acabar com miséria no país e que hoje é copiado pelo mundo todo". (DIÁRIO DA CÂMARA DOS DEPUTADOS, 17 maio 2003, p. 21228).

Portanto, o PFZ traz consigo, em um primeiro momento, uma ação emergencial de distribuição de alimentos, mas não se restringe a isso. Para seus defensores, ele acarreta várias outras medidas articuladas, ou seja, além de emergencial, é um programa que visa a mudar essa situação social em que se encontra o país, como coloca a deputada Ângela Guadagnin (PT-SP):

Apesar de todas as críticas e dúvidas que muitas pessoas demonstram ter quanto ao Programa Fome 
Zero, esclareceu que esse projeto tem uma meta muito clara, qual seja, a de inverter a situação de injustiça social e de exclusão que existe neste país, e as ações já começaram a ser implementadas pelos ministérios de seu governo, mostrando assim quais são as prioridades de sua gestão. (DIÁRIO DA CÂMARA DOS DEPUTADOS, 15 mar. 2003, p. 09509).

Nesse contexto em que se encontra o PFZ e o governo Lula, entre críticas quanto ao seu caráter assistencialista e à sua execução, e, por outro lado, visto como um governo que se preocupa com o social, principalmente com as classes mais baixas, o deputado Luizinho (PT-SP) caracteriza da seguinte forma o governo Lula e o Programa Fome Zero: "esses são alguns momentos que marcam o início de um governo diferente, que tem como marco o Programa Fome Zero" (DIÁRIO DA CÂMARA DOS DEPUTADOS, 07 mar. 2003, p. 04977).

Com isso, o governo Lula é significado como um "governo diferente" e suas diferenças são calcadas na preocupação com o social, na luta contra a fome, sendo o Programa Fome Zero o seu marco, a sua principal bandeira de luta.

\section{Considerações finais}

Buscou-se demonstrar como os deputados federais do PFL e do PT caracterizaram o PFZ, um programa social que foi elaborado e implementado por um partido de esquerda que, desde o seu lançamento, sofreu críticas e elogios tanto quanto à sua execução como também em relação à sua implementação e estruturação.

Pôde ser observado que uma das principais críticas dos deputados do PFL ao PFZ foi referente à sua execução, tendo como principal argumento o caráter assistencialista do programa, ou seja, restringindo as ações do PFZ simplesmente à distribuição de alimentos e do cartão-alimentação. Ainda, pôde-se observar que outra recorrente crítica ao PFZ estava relacionada a sua estruturação, pelo argumento produzido pelos deputados pefelistas de não haver políticas voltadas para combater esse flagelo na origem. Nesse sentido, esses parlamentares apontaram meios de agir para se ter um verdadeiro combate à fome no Brasil, buscando articular o PFZ com outras medidas paralelas, tendo como forte argumento a geração de emprego e renda.
Em tal contexto, o PFL se mostrou, em muitos momentos dos pronunciamentos de seus deputados, contrário à forma como o programa estava sendo conduzido, como estava sendo implementado pelo governo Lula, pois, para esse partido, o programa não passava de uma medida assistencialista, nele não havendo um projeto para efetivamente retirar as famílias assistidas do estado de pobreza em que se encontravam, tendo, assim, mero caráter paternalista e clientelista.

Notou-se, também, que nem todos os pronunciamentos dos deputados do PFL se mostraram contrários ao programa. Em alguns momentos, ficou relatado o apoio ao PFZ, pois, segundo tais deputados, esse é um programa de grande importância e com um caráter moralmente elogiável.

Já para os defensores do PFZ, neste caso os deputados do PT, os argumentos se mostram quase sempre em resposta às críticas feitas ao programa. Neste particular, os deputados petistas argumentavam que o PFZ não se restringia à esfera emergencial, ou seja, a mera distribuição de alimentos, como acusaram sobremaneira os parlamentares liberais. Ao contrário, para os petistas, essa ação era apenas um primeiro momento do PFZ.

Assim, além desse primeiro momento, emergencial, na linguagem de seus defensores, o programa também buscava abranger muitas outras ações articuladas para combater a fome no Brasil, sendo objeto de intensas negociações entre a maioria dos ministérios, além de setores da sociedade civil engajados na luta pela erradicação da fome, talvez o maior dos flagelos brasileiros.

Portanto, a disputa discursiva entre os deputados do PT e do PFL construiu um ponto nodal, no qual se marcava a fronteira entre os defensores do programa e os que se colocavam contra ele, formando com isso dois polos antagônicos. Dentro dessa disputa, as posições ideológicas dos deputados aparecem como uma representação de seu partido, no caso do PT defendendo e no caso do PFL atacando o PFZ, programa esse elaborado pelo governo Lula, situação, que sofreu oposição do PFL.

\section{Referências}

ABRAMOVAY, Ricardo. O que é fome? São Paulo: Brasiliense, 1980. 
ALTHUSSER, Louis. Aparelhos ideológicos do Estado. 6. ed. Rio de Janeiro: Graal, 1985.

ANANIAS, Patrus. Fome Zero. 2004. Disponível em: $<$ http://www.mds.gov.br/noticias_antigas/noticia473.htm/ html2pdf $>$.

BELIK, Walter; DEL GROSSI, Mauro. O Programa Fome Zero no contexto das políticas sociais no Brasil. 2003. Disponível em: <http://www.fomezero.gov.br/download/>.

BOBBIO, Norberto. Direita e esquerda: razões e significados de uma distinção política. São Paulo: ABDR, 1995.

CARTA DA VITÓRIA. 2002. Disponível em: <http:// www.pt.org.br/portalpt/images/stories/arquivos/ compromissocomamudanca.pdf $>$.

CASTRO, Claudia de Moura; COIMBRA, Marcos. O problema alimentar no Brasil. Campinas: Unicamp, 1985.

FOUCAULT, Michel. A arqueologia do saber. 5. ed. Rio de Janeiro: Forense Universitária, 1997.

GEORGE, Susan. O Mercado da fome: as verdadeiras razões da fome no mundo. Rio de Janeiro: Paz e Terra, 1978.

HOMEM DE MELO, Fernando. O problema alimentar no Brasil: a importância dos desequilíbrios tecnológicos. Rio de Janeiro: Paz e Terra, 1983.

LACLAU, Ernesto; MOUFFE, Chantal. Hegemonia y estrategia socialista: hacia uma nova radicalización de la democracia. Buenos Aires: Fondo de Cultura Econômica de Argentina, 2004.

Identity and hegemony: the role of universality in the constitution of political logics. In: BUTLER, Judith; LACLAU, Ernesto; ZIZEK, Slavoj. Contingency, hegemony, universality: contemporary dialogues on the left. Londres: Verso, 2000.

Nuevas reflexiones sobre la revolución de nuestro tiempo. 2. ed. Buenos Aires: Nueva Visión, 2000.

$\frac{}{1996 .}$. Emancipación y diferencia. Buenos Aires: Ariel,

. La razón populista. Buenos Aires: FCE, 2005.

LAHORQUE, Mario Leal. A esquerda no poder local: Porto Alegre e o Partido dos Trabalhadores. Scripta Nova, Barcelona, v. 11, n. 245 (16), 2007.

MAINGUENEAU, Dominique. Termos-chave da análise do discurso. Belo Horizonte: Editora UFMG, 2000.

MAINWARING, Scott. Sistemas partidários em novas democracias: o caso do Brasil. Rio de Janeiro, Mercado Aberto, 2001.
; MENEGUELLO, Rachel; POWER, Timoty. Partidos conservadores no Brasil contemporâneo: quais são, o que defendem, quais são suas bases. São Paulo: Paz e Terra, 2000.

PT- PARTIDO DOS TRABALHADORES. Manifesto. (1980) Disponível em: <http://www.pt.org.br/portalpt/ images/stories/arquivos/manifesto.pdf $>$.

MINAYO, Maria Cecília de Souza (Org.). Raízes da fome. 3. ed. Petrópolis: Vozes, 1987.

RODRIGUES Martins, Leôncio. Quem é quem na Constituinte: uma análise sociopolítica dos partidos e deputados. São Paulo: Oesp/Maltese, 1987.

SILVA, José Graziano da; BELIK, Walter; TAKAGI, Maya. Para os críticos do Fome Zero. (2003) Disponível em: $<$ http://www.fomezero.gov.br/download/50fomezero2.pdf $>$. Acesso em: 01 jul. 2009.

SOARES, Gilbergues Santos. Os partidos políticos de esquerda e a consolidação da democracia brasileira. Interfaces, Caruaru, v. 6, n. 2, 2006.

YASBEK, Maria Carmelita. O Programa Fome Zero no contexto das políticas sociais brasileiras. São Paulo em Perspectiva, v. 18, n. 2, 2004, p. 104-12.

Fome Zero: uma política social em questão. Saúde e Sociedade, v. 12, n. 1, p. 43-50, 2003. 